\title{
The effect of cavities and T-shaped assembly of fins on overall thermal resistances
}

\author{
Eylem Cetin, Erdal Cetkin* \\ Izmir Institute of Technology, Department of Mechanical Engineering, Urla, Izmir 35430, Turkey \\ Email: erdalcetkin@iyte.edu.tr
}

\begin{abstract}
In this study, authors show that maximum excess temperature on a heat generating cylindrical solid domain can be minimized with numerically optimized rectangular cavities and T-shaped fins. The effect of the cavities and the fins on overall thermal resistances were compared while their volume fraction in a unit volume element is fixed. Furthermore, the designs correspond to the minimum thermal resistance were uncovered for two types of flows; parallel and cross-flow. The governing equations of the heat transfer and the fluid flow were solved simultaneously in order to show the effects of design on the flow characteristics and the thermal performance. Two-dimensional solution domain was used to uncover the thermal performance in cross-flow case because the flow direction is perpendicular to the heat transfer surface area of the heat generating domain. However, three-dimensional domain was used in parallel flow case because the fluid flows along the outer surface of the heat generating domain. For the cross-flow case, the results show that T-shaped assembly of fins with longer stem and shorter tributaries correspond to the lower peak temperature. In addition, the results also show that there is an optimal cavity shape that minimizes the peak temperature. This optimal shape becomes thinner when the number of the cavities increase. In parallel flow case, fins with thicker and shorter stem and longer tributaries correspond to the minimum excess temperature. In addition, the longer and thinner cavities increase the thermal performance in parallel flow case.
\end{abstract}

Keywords: Constructal Law, Heat Transfer Enhancement, Cavity, Fin, Convective Heat Transfer.

\section{INTRODUCTION}

Advanced technologies with the trend of miniaturization requires cooling under extreme heating loads per unit volume [1]. The current literature shows that the overall thermal resistances can be minimized by altering the design of heat generating domain and/or extended surfaces when the temperature difference is constant. The current literature also shows the design corresponding to the maximum heat transfer rate is similar to the designs in the nature. For instance, Cetkin and Oliani [2] showed that the shape of the high-conductivity pathways inserted in a heat generating domain should be similar to the roots of plants. The shapes exist in the nature can be considered as designs with selfassembly feature, however, it should be noted that the current literature also shows these structures were assembled such that the resistance to the flow is minimum [3]. Depending on the objectives of the structures, this flow can correspond to the flow of heat, fluid, and/or stress. Adrian Bejan stated Constructal Law in order to explain this phenomenon which can be quoted as; "For a finite-size flow system to persist in time (to live), its configuration must change in time such that it provides easier and easier access to its currents" (fluid, energy, species, etc.) [3-4]. The current literature shows the distinct flow configurations (such as river-delta [3], economy
[5], sports[6], lungs [7], heat generating domain with highconductivity inserts [8], thermodynamic optimization [9] and many more) can be explained or designed in consideration with the constructal law.

Here authors focus on the minimization of overall thermal resistances (heat transfer rate enhancement). Bejan and Almogbel documented the geometry of T-shaped fin structure which corresponds to the maximum heat transfer rate [10]. Lorenzini et al. documented the numerical simulation results of Ref. [10] in order to increase the practicality of the results for industrial applications [11]. Biserni et al. documented the geometry of T-shaped fins that corresponds to the minimized maximum excess temperature where the fins are attached to a cylindrical heat generating body with constant heat generation rate [12]. Hazarika et al. revealed analytical solution to predict optimum design parameter of Constructal T-shaped fin for heat and mass transfer (condensation of moisture) [13]. The current literature also documents various $\mathrm{T}$ - and $\mathrm{Y}$-shaped fin geometries corresponding to the minimum resistance to the heat flow relative to the different boundary conditions and constraints [14-16]. Furthermore, the effect of the inverted fins (cavities filled with high-conductivity inserts) on the maximum temperature and heat transfer rate were documented in the literature $[17,18]$. On the contrary to the 
fins, the inverted fins decrease the resistance to the heat flow in a conductive medium [19].

Biserni et al. documented the shape of the optimized rectangular and $\mathrm{T}$-shaped cavities, and then the thermal performance of these cavities was compared with each other [20]. In addition, there are studies about rectangular and $\mathrm{T}$ shaped cavities documented in the literature [21-22]. Lorenzini et al. documents the constructal Y-shaped cavities with genetic algorithms which correspond to the minimum peak temperature [23]. Lorenzini and Rocha documented the $\mathrm{T}$ - and Y-shaped cavity geometries optimized according to the constructal law [24]. Later, Lorenzini et al. documented the optimized complex geometries of T-Y-shaped cavities with lateral intrusions cooled by convection [25]. Lorenzini et al. uncovers what should be the length scales of the rectangular cavity inserted into a heat generating cylindrical body in order to achieve minimum excess temperature [26].

The current literature focuses on the geometry optimization of fins and cavities with constant convective heat transfer boundary conditions. However, alterations in the geometry of fins and cavities disturb the velocity field in the fluid flow region which affects the convective heat transfer coefficient. Here, the fluid flow and heat transfer parts of the convection problem were solved simultaneously in order to uncover the effect of shape on both the heat transfer surface area increment and the change in the fluid flow. Here, authors also document the shape of the fins and cavities corresponding to the maximum heat transfer rate for both parallel and cross flows.

\section{CROSS-FLOW}

\subsection{T-shaped fins}

\subsubsection{Model}

Consider a heat generating cylinder with attached $\mathrm{T}$ shaped fins in a two-dimensional unit element, Fig 1. The thermal conductivity of the heat generating domain, (q"'), with the size of $\pi \times \mathrm{R}^{2}$ is $\mathrm{k}_{\mathrm{c}}$. The thermal conductivity of the T-shaped fins with length scales of $\left(\mathrm{L}_{1}, \mathrm{t}_{1}\right)$ and $\left(\mathrm{L}_{0}, \mathrm{t}_{0}\right)$ are $\mathrm{k}_{\mathrm{t}}$, and they are placed symmetrically upon the solid body. The area of the fluid domain is fixed, $\mathrm{H}_{\mathrm{f}} \times \mathrm{L}_{\mathrm{f}}$, and assumed as 50 times greater than the size of heat generating domain while $\mathrm{H}_{\mathrm{f}}$ and $\mathrm{L}_{\mathrm{f}}$ can vary. The thermal conductivity of the fluid is $\mathrm{k}_{\mathrm{f}}$. The area fraction of $\mathrm{T}$-assembly of fins over cylindrical solid body is $\varphi_{t}=N_{t}\left(2 L_{0} t_{0}+L_{1} t_{1}\right) / \pi R^{2}$ where $N_{t}$ is number of fins, and the area which is restricted by one T-shaped fin is $\psi=2 \mathrm{~L}_{0}$ $\mathrm{L}_{1} / \pi \mathrm{R}^{2}$. Two edges of the fluid domain were described as inlet and outlet boundary condition with the size of $\mathrm{H}_{\mathrm{f}}$. Additionally, symmetry boundary condition was implemented on the remaining edges of the fluid domain with the length scale of $\mathrm{L}_{\mathrm{f}}$. Distance in between the tips of fins and the edges that symmetry boundary condition was kept constant as $2 \times \mathrm{R}$.

In addition, the temperature difference between the fins facing each other is relatively small to yield a sensible radiative heat transfer between them. Therefore, the effect of radiative fluxes is assumed to be negligibly small in comparison to convective and conductive fluxes throughout the simulations

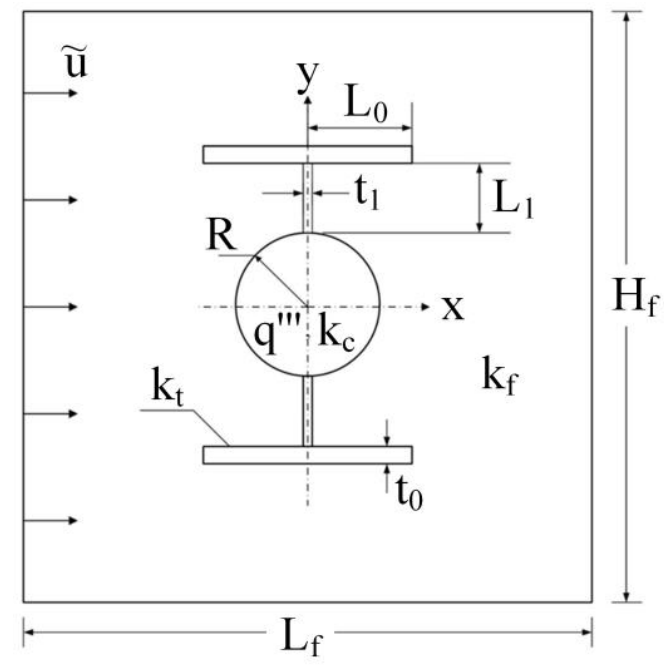

Figure 1. Heat generating domain with T-shaped fins

Throughout the numerical study, Navier-Stokes and Energy equations were solved simultaneously in coupled form. The fluid flow is incompressible and laminar. Heat generation is uniform throughout the heat generating cylindrical domain. Isotropic materials with constant material properties were considered. With these simplifications in mind, Navier-Stokes and Energy equations for the fluid domain become

$\frac{\partial \mathrm{u}}{\partial \mathrm{x}}+\frac{\partial \mathrm{v}}{\partial \mathrm{y}}=0$

$u \frac{\partial \mathrm{u}}{\partial \mathrm{x}}+v \frac{\partial \mathrm{u}}{\partial \mathrm{y}}=-\frac{1}{\rho} \frac{\partial \mathrm{P}}{\partial \mathrm{x}}+v\left(\frac{\partial^{2} \mathrm{u}}{\partial \mathrm{x}^{2}}+\frac{\partial^{2} \mathrm{u}}{\partial \mathrm{y}^{2}}\right)$

$u \frac{\partial \mathrm{v}}{\partial \mathrm{x}}+v \frac{\partial \mathrm{v}}{\partial \mathrm{y}}=-\frac{1}{\rho} \frac{\partial \mathrm{P}}{\partial \mathrm{y}}+v\left(\frac{\partial^{2} \mathrm{v}}{\partial \mathrm{x}^{2}}+\frac{\partial^{2} \mathrm{v}}{\partial \mathrm{y}^{2}}\right)$

$\rho c_{p}\left(u \frac{\partial \mathbf{T}}{\partial \mathbf{x}}+v \frac{\partial \mathbf{T}}{\partial \mathbf{y}}\right)=k_{f}\left(\frac{\partial^{2} \mathbf{T}}{\partial \mathbf{x}^{2}}+\frac{\partial^{2} \mathbf{T}}{\partial \mathbf{y}^{2}}\right)$

Here, $\mathrm{x}$ and $\mathrm{y}$ are spatial coordinates, and $\mathrm{u}$ and $\mathrm{v}$ are the velocity components corresponding to these coordinates, respectively. In addition, $\mathrm{P}, \rho, v, \mathrm{c}_{\mathrm{p}}$ are pressure, density, kinematic viscosity and specific heat at constant pressure of the fluid, respectively.

Energy equations for the heat generating domain and the fins become

$\frac{\partial^{2} T}{\partial \mathrm{x}^{2}}+\frac{\partial^{2} T}{\partial \mathrm{y}^{2}}+\frac{q^{\prime \prime \prime}}{k_{c}}=0 \quad \frac{\partial^{2} T}{\partial \mathrm{x}^{2}}+\frac{\partial^{2} T}{\partial \mathrm{y}^{2}}=0$

In order to deduce the dimensionless governing equations, the following non-dimensionalization parameters were selected

$(\tilde{x}, \tilde{y})=\frac{(x, y)}{D} \quad(\tilde{u}, \tilde{v})=\frac{(u, v) D}{v} \quad \tilde{T}=\frac{\left(T-T_{r e f}\right) k_{f}}{q^{\prime \prime \prime} D^{2}} \quad \tilde{P}=\frac{\left(P-P_{r f}\right) D^{2}}{\mu \alpha}$

Dimensionless Navier-Stokes and Energy equations become 
$\frac{\partial \tilde{\mathbf{u}}}{\partial \tilde{\mathbf{x}}}+\frac{\partial \tilde{\mathbf{v}}}{\partial \tilde{\mathbf{y}}}=0$

$\tilde{u} \frac{\partial \tilde{\mathbf{u}}}{\partial \tilde{\mathbf{x}}}+\tilde{v} \frac{\partial \tilde{\mathbf{u}}}{\partial \tilde{\mathbf{y}}}=-\frac{1}{\operatorname{Pr}} \frac{\partial \tilde{\mathbf{P}}}{\partial \tilde{\mathbf{x}}}+\left(\frac{\partial^{2} \tilde{\mathbf{u}}}{\partial \tilde{\mathbf{x}}^{2}}+\frac{\partial^{2} \tilde{\mathbf{u}}}{\partial \tilde{\mathbf{y}}^{2}}\right)$

$\tilde{u} \frac{\partial \widetilde{\mathbf{v}}}{\partial \tilde{\mathbf{x}}}+\tilde{v} \frac{\partial \widetilde{\mathbf{v}}}{\partial \tilde{\mathbf{y}}}=-\frac{1}{\operatorname{Pr}} \frac{\partial \widetilde{\mathbf{P}}}{\partial \tilde{\mathbf{y}}}+\left(\frac{\partial^{2} \tilde{\mathbf{v}}}{\partial \tilde{\mathbf{x}}^{2}}+\frac{\partial^{2} \tilde{\mathbf{v}}}{\partial \tilde{\mathbf{y}}^{2}}\right)$

$\tilde{u} \frac{\partial \widetilde{\mathbf{T}}}{\partial \widetilde{\mathbf{x}}}+\tilde{v} \frac{\partial \widetilde{\mathbf{T}}}{\partial \widetilde{\mathbf{y}}}=\frac{1}{\operatorname{Pr}}\left(\frac{\partial^{2} \widetilde{\mathbf{T}}}{\partial \widetilde{\mathbf{x}}^{2}}+\frac{\partial^{2} \widetilde{\mathbf{T}}}{\partial \tilde{\mathbf{y}}^{2}}\right)$

$$
\begin{gathered}
\frac{\partial^{2} \tilde{T}}{\partial \tilde{\mathrm{x}}^{2}}+\frac{\partial^{2} \tilde{T}}{\partial \tilde{\mathrm{y}}^{2}}+\frac{k_{f}}{k_{c}}=0 \\
\frac{\partial^{2} \tilde{T}}{\partial \tilde{\mathrm{x}}^{2}}+\frac{\partial^{2} \tilde{T}}{\partial \tilde{\mathrm{y}}^{2}}=0
\end{gathered}
$$

where Pr is Prandtl number.

The conservation of energy at the interfaces between the cylindrical domain, fins, and the fluid domain require

$$
\left.\frac{\partial \tilde{T}}{\partial \tilde{\mathbf{n}}}\right|_{i}=\left.\frac{\partial \tilde{T}}{\partial \tilde{\mathbf{n}}}\right|_{j} \frac{k_{j}}{k_{i}}
$$

where $i$ and $j$ are indexes representing fin $(t)$, cylinder $(c)$ and fluid (f). Therefore, the ratio of $\mathrm{k}_{\mathrm{j}} / \mathrm{k}_{\mathrm{i}}$ corresponds to the ratio of thermal conductivities of the two domains connected at each interface. The ratio of the thermal conductivities between fin - cylinder, fluid - fin and fluid - cylinder are chosen as 200, 0.0005 and 0.01 , respectively.

Dimensionless Navier-Stokes and Energy equations were solved via a finite element software [27]. Quadratic shape functions were used for the discretization of the equations. Relative errors for the convergence of continuity, momentum and energy equations during the iterations were specified as $10^{-7}$. Table 1 shows that the simulation results become independent of mesh size with 197458 number of mesh elements where the criterion is the maximum relative error for temperature being less than $10^{-4}$. Here, $n$ and $n+1$ represents the results for the coarse and finer meshes.

Table 1. Mesh dependency test for T-shaped fin model with $\mathrm{Re}=100$ and $\mathrm{N}_{\mathrm{t}}=2$

\begin{tabular}{ccc}
\hline $\begin{array}{c}\text { No of Mesh } \\
\text { Elements }\end{array}$ & $\widetilde{T}_{\text {max }}$ & $\left|\widetilde{T}_{\text {max }}^{m+1} \tilde{T}_{\text {max }}^{m}\right| / \tilde{T}_{\text {max }}^{m}$ \\
\hline 2934 & 2.11357585 & $1.4045 \times 10^{-1}$ \\
\hline 9282 & 2.41042735 & $5.0792 \times 10^{-2}$ \\
\hline 69450 & 2.53285729 & $8.5639 \times 10^{-4}$ \\
\hline 119168 & 2.53502641 & $6.0999 \times 10^{-4}$ \\
\hline 197458 & 2.53657274 & $8.7208 \times 10^{-5}$ \\
\hline 241470 & 2.53679395 & \\
\hline
\end{tabular}

Figure 2 shows the validation of current numerical study relative to Ref. [12]. The change of the peak temperature according to different $\left(\mathrm{t}_{1} / \mathrm{t}_{0}\right)$ and $\left(\mathrm{L}_{1} / \mathrm{L}_{0}\right)$ ratios can be seen in the Fig. 2. It denotes that there is an optimal ratio $\left(t_{1} / t_{0}\right)$ which varies with different $\left(\mathrm{L}_{1} / \mathrm{L}_{0}\right)$ ratios under assumptions of the constant heat transfer coefficient and adiabatic outer surface of the heat generating cylinder. Figure 2 shows the results of the current study is in accord with the published results of Ref. [12].

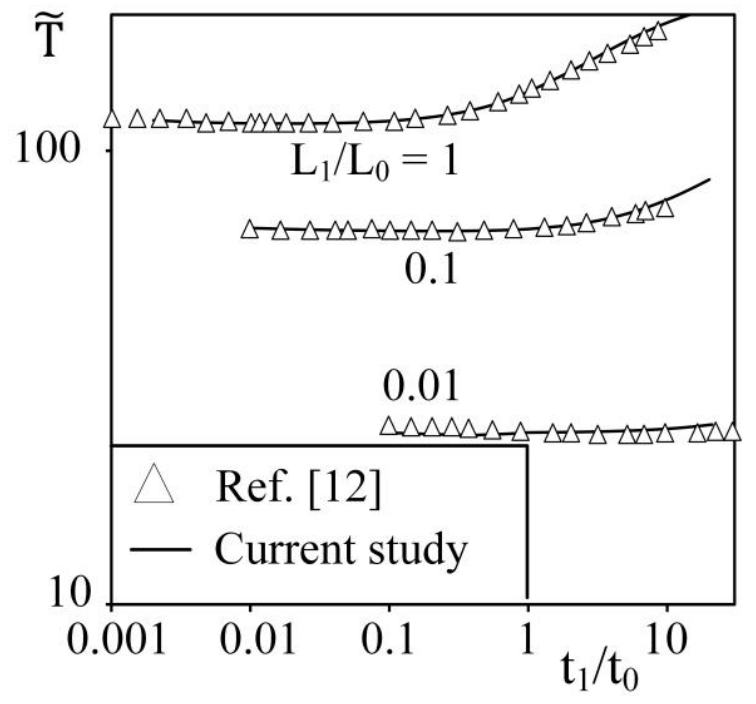

Figure 2. Validation of the current results (fins) relative to the results of Ref. [12]

\subsubsection{Results}

Figure 3 denotes how the geometrical parameters affect the peak temperature with inserted T-shaped fins. The minimum peak temperature value corresponds to the minimum overall thermal resistance which is specified as the ratio of the temperature difference and the heat transfer rate (heat transfer rate is constant due to constant heat generation). The change of the peak temperature according to different values of the parameter $\psi$ can be seen in the Fig. 3a. The shape of fins becomes thinner and longer while the parameter $\psi$ increases. Figure $3 \mathrm{a}$ shows that thin and long fins have better thermal performance. Figure $3 \mathrm{~b}$ shows that there is an optimal $\left(\mathrm{t}_{1} / \mathrm{t}_{0}\right)$ ratio which corresponds to the minimum peak temperature when $\psi=1$. The optimal ratio increases as $\left(\mathrm{L}_{1} / \mathrm{L}_{0}\right)$ ratio decreases from 2 to 0.02 . Another parameter that affects the peak temperature is the number of fins, $\mathrm{N}_{\mathrm{t}}$. Figure $3 \mathrm{c}$ shows the effect of different $\left(\mathrm{L}_{1} / \mathrm{L}_{0}\right)$ ratios on thermal performance when $\mathrm{N}_{\mathrm{t}}$ equals to 2,4 and 8 . The thermal resistance is smallest when $\mathrm{N}_{\mathrm{t}}$ equals to 8 . While $\left(\mathrm{L}_{1} / \mathrm{L}_{0}\right)$ ratio increases up to 2 , the 4 fins correspond to higher thermal performance than 2 fins configuration. However, as this ratio increases from 2 to 5,2 fins shows better thermal performance than the 4 fins configuration. The reason for this behavior is due to the thermal boundary layers formed at the fin which located closest to the fluid entrance. These thermal boundary layers behave similar to an insulation layer (due to decreased temperature difference on the fin surface and surrounding fluid) on the fins located at the top and bottom. Increasing the $\mathrm{L}_{1} / \mathrm{L}_{0}$ ratio increases the thermal boundary thickness experienced on the top and bottom fins. The decreased temperature difference becomes more dominant on the heat transfer rate than the increase in the heat transfer surface area as $\mathrm{L}_{1} / \mathrm{L}_{0}$ becomes greater than 2 for 4 fins.

Figure 4 shows the temperature distribution and velocity streamlines of the configurations with $\mathrm{N}_{\mathrm{t}}=4, \mathrm{~L}_{1} / \mathrm{L}_{0}=0.5$ and $t_{1} / t_{0}=5$, and $L_{1} / L_{0}=5$ and $t_{1} / t_{0}=4$. In Figure $4 a$, the length of tributaries is so long that it will form an almost closed square, therefore, the fluid cannot reach the heat generating cylinder and the stems easily. Therefore, the deficiency of circulation weakens convective heat transfer around the cylinder and the stems. In addition, Figure 4 shows that the fluid in between the two adjacent fins yields cavity type flow which can be 
seen from the streamlines. Furthermore, Figure 4 shows that the convective heat transfer becomes more pronounced due to the cavity flow in between the adjacent stems as the $\mathrm{L}_{1} / \mathrm{L}_{0}$ ratio increases. Therefore, even the tributary surface area is greater in Fig. 4a, the peak temperature is smaller in Fig. 4b.
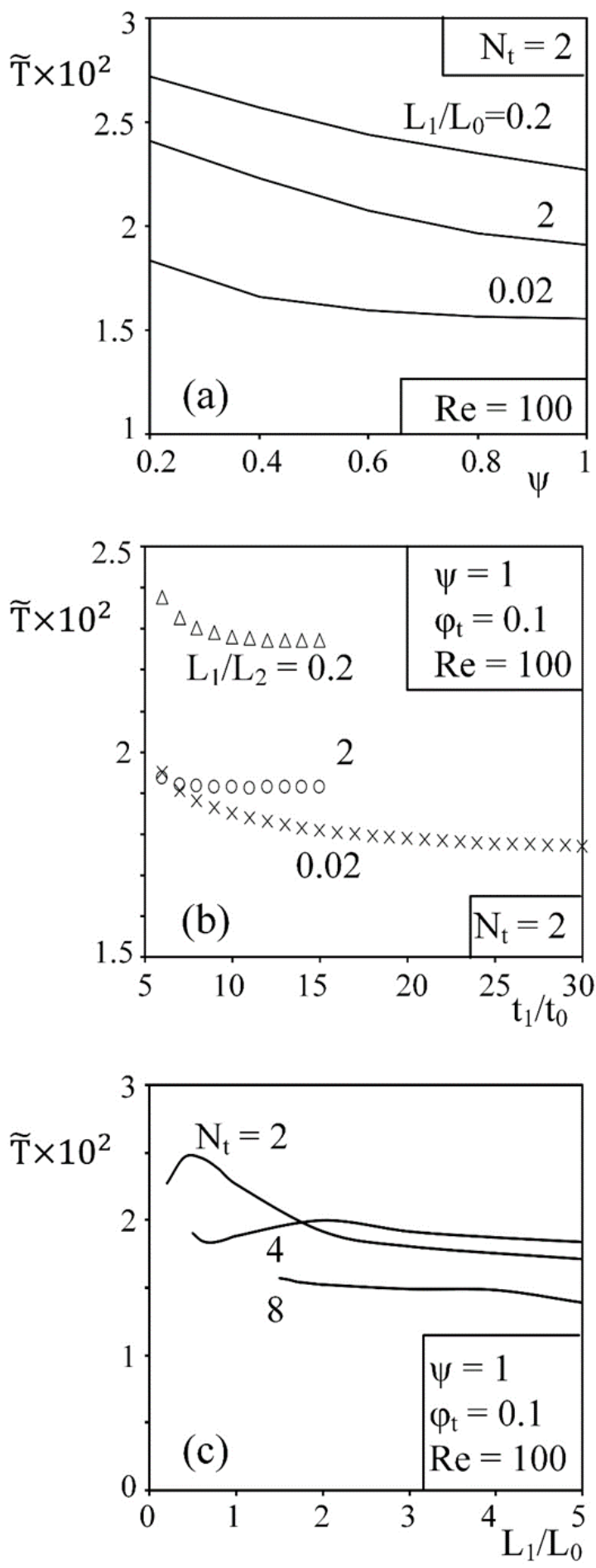

Figure 3. The maximum excess temperature relative to (a) $\psi$, (b) $\left(\mathrm{t}_{1} / \mathrm{t}_{0}\right)$ for various $\left(\mathrm{L}_{1} / \mathrm{L}_{0}\right),(\mathrm{c})\left(\mathrm{L}_{1} / \mathrm{L}_{0}\right)$ for various $\mathrm{Nt}$

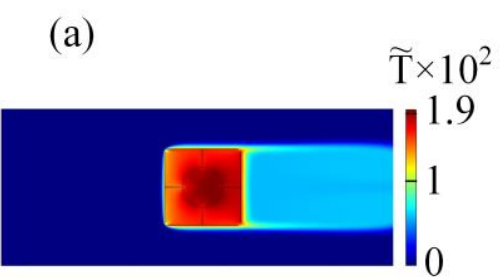

(b)
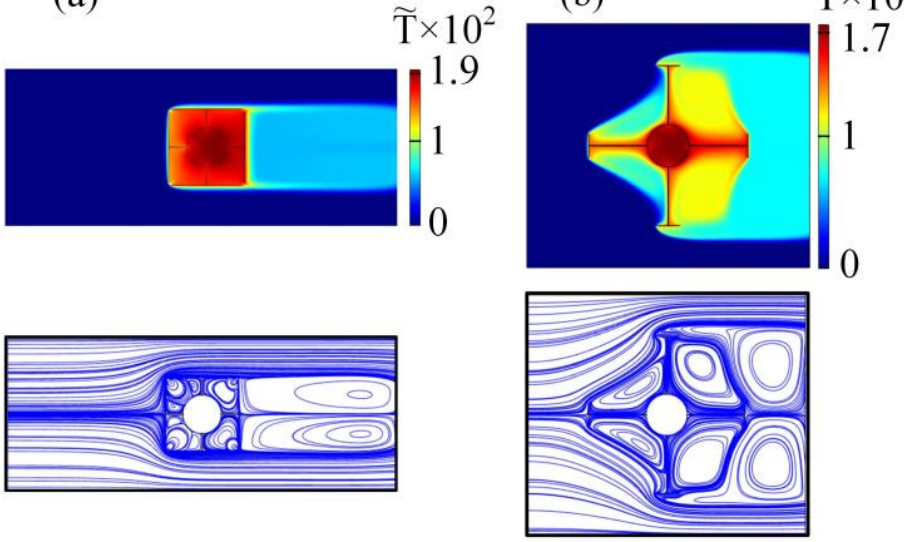

Figure 4. Temperature distribution and velocity streamlines (a) $\mathrm{L}_{1} / \mathrm{L}_{0}=0.5$ and $\mathrm{t}_{1} / \mathrm{t}_{0}=5$ and (b) $\mathrm{L}_{1} / \mathrm{L}_{0}=5$ and $\mathrm{t}_{1} / \mathrm{t}_{0}=4$

\subsection{Cavities}

\subsubsection{Model}

Consider a heat generating domain in which rectangular shaped cavities inserted, as shown in Fig. 5. There are two constraints; total area $\left(\mathrm{A}=\pi \times \mathrm{R}^{2}\right)$ and total cavity area $\left(\mathrm{A}_{\mathrm{cv}}=\mathrm{N}_{\mathrm{cv}} \times \mathrm{H}_{\mathrm{cv}} \times \mathrm{L}_{\mathrm{cv}}\right)$ where $\mathrm{N}_{\mathrm{cv}}$ represents the number of cavities.

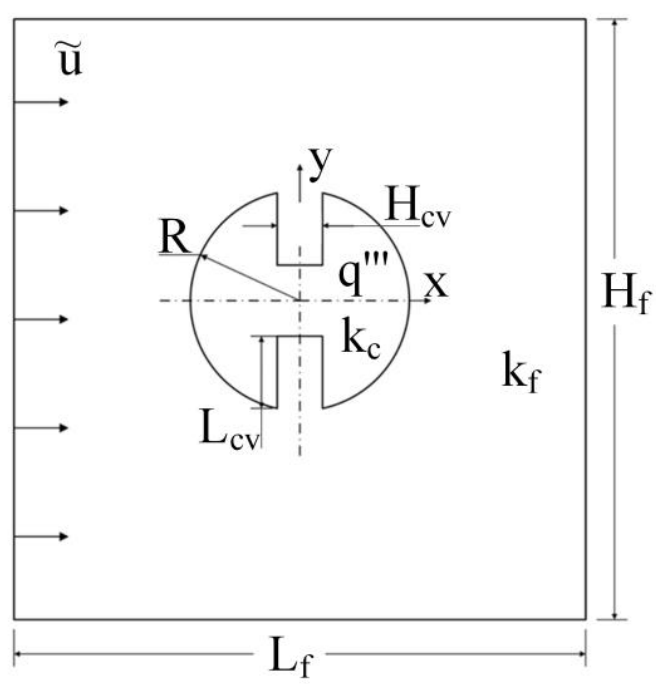

Figure 5. Heat generating domain with cavities

The area fraction between the total cavity area and the total area is $\varphi_{\mathrm{cv}}=\mathrm{A}_{\mathrm{cv}} / \mathrm{A}$.

The fluid domain $\left(\mathrm{H}_{\mathrm{f}} \times \mathrm{L}_{\mathrm{f}}\right)$ is 50 times greater than total area of the heat generating solid and the cavities $\left(\pi \times R^{2}\right)$ similar to the T-shaped fins of Fig. 1. Furthermore, the top and bottom edges of the domain are symmetry boundaries and the distance in between the heat generating domain and the symmetry boundaries is fixed as $3 \times \mathrm{R}$ throughout the analyses.

The conservation of mass, momentum and energy were solved in dimensionless form as shown in Eqs. (7) - (11) and described in details in Section 2.1.1. Here, the only difference is the absence of the fins. Therefore, the energy equation for the fin domain and conservation of the energy at the interface of the fin-fluid and fin-cylinder are absent. 
Table 2. Mesh dependency test for cavities when $\mathrm{Re}=100$ and $\mathrm{N}_{\mathrm{cv}}=4$

\begin{tabular}{lll}
\hline $\begin{array}{l}\text { No of Mesh } \\
\text { Elements }\end{array}$ & $\widetilde{T}_{\max }$ & $\left|\tilde{T}_{\max }^{n+1}-\tilde{T}_{\max }^{n}\right| / \widetilde{T}_{\max }^{n}$ \\
\hline 8518 & 2.2721845 & $6.076 \times 10^{-3}$ \\
\hline 17840 & 2.2859904 & $7.949 \times 10^{-3}$ \\
\hline 198516 & 2.3057642 & $3.930 \times 10^{-5}$ \\
\hline 252246 & 2.30585479 & \\
\hline
\end{tabular}

Mesh independency test was performed in order to uncover which mesh density corresponds to the criterion of maximum relative temperature being less than $10^{-4}$. Table 2 shows the relation between the number of mesh elements and the maximum temperature in the domain.

In addition, Figure 6 shows the comparison of the current results with the results of Ref. [26] where the effect of the cavity aspect ratio $\mathrm{H}_{\mathrm{cv}} / \mathrm{L}_{\mathrm{cv}}$ on the peak temperature is documented. Figure 6 shows the results of the current study agrees with the published results of the Ref. [26].

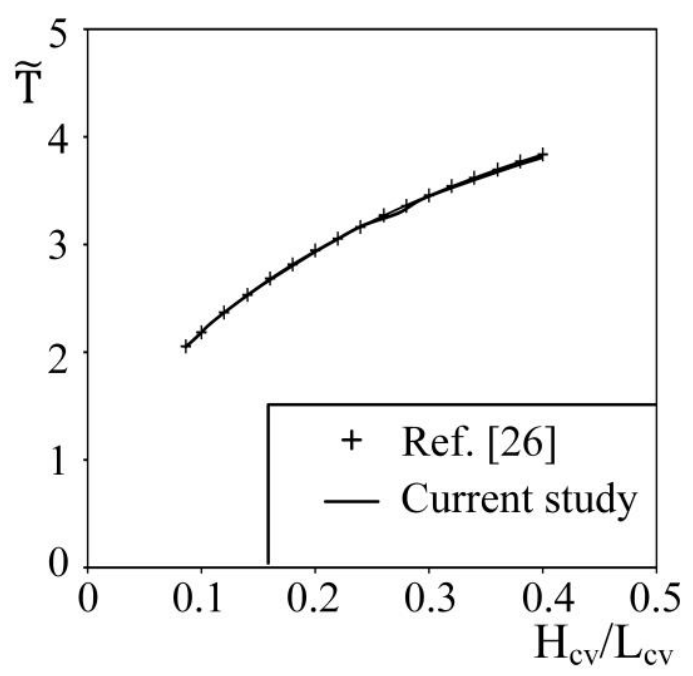

Figure 6. Comparison of the results of current study and Ref. [26].

\subsubsection{Results}

Figure 7 shows that there is an optimum aspect ratio $\left(\mathrm{H}_{\mathrm{cv}} / \mathrm{L}_{\mathrm{cv}}\right)$ which minimizes maximum excess temperature, when $\mathrm{N}_{\mathrm{cv}}$ equals to 2, 4 and 8 . It can be seen from the Fig. 7 that the optimal aspect ratio decreases as the number of cavities increases. Lower $\mathrm{H}_{\mathrm{c} v} \mathrm{~L}_{\mathrm{cv}}$ ratio corresponds to thinner and longer cavity shape while the number of the cavities and $\varphi_{\mathrm{cv}}$ are fixed. For the same $\mathrm{H}_{\mathrm{cr}} \mathrm{L}_{\mathrm{cv}}$, the shape of a cavity becomes thinner and shorter as $\mathrm{N}_{\mathrm{cv}}$ increases. The cavity shape corresponds to the minimum peak temperature also becomes thinner and shorter when $\mathrm{N}_{\mathrm{cv}}$ increases. Therefore, the optimal cavity shape for the 8 cavities configurations is the thinnest and shortest one among the all configurations, as shown in Fig. 7.

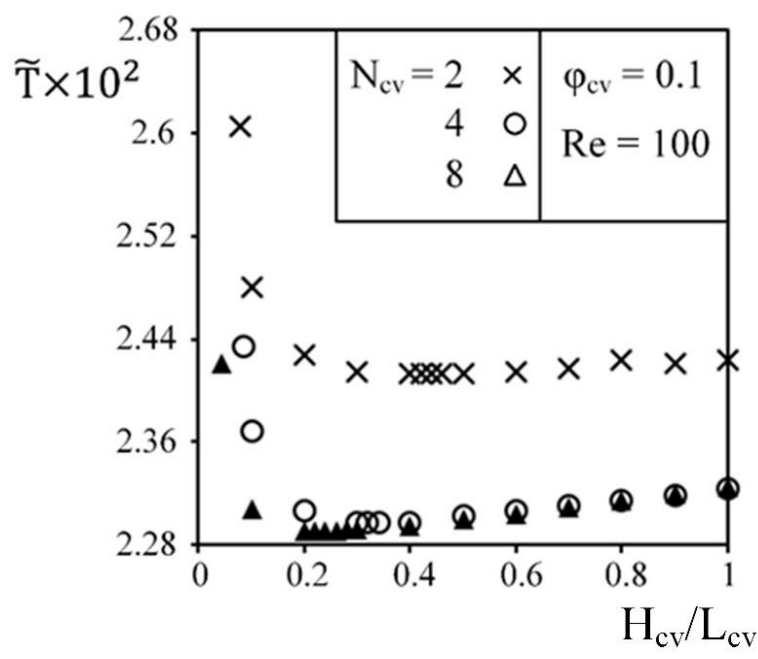

Figure 7. The effect of $\mathrm{H}_{\mathrm{cv}} / \mathrm{L}_{\mathrm{cv}}$ on the thermal performance

Temperature distributions and velocity streamlines of the configurations that specified in Fig. 7 are given in Fig. 8 . Figure 8 shows that both the peak temperature and the domain occupied by the peak temperature decreases as $\mathrm{N}_{\mathrm{cv}}$ increases. In addition, the decrease in the peak temperature diminishes as the number of cavities increases. For instance, the peak temperature decreases $5 \%$ and $0.3 \%$ as $\mathrm{N}_{\mathrm{cv}}$ increases from 2 to 4 and from 4 to 8 . Velocity streamlines of Fig. 8 show that the fluid in the cavities flows with different characteristics depending on their position. However, flow in the most of the cavities can be specified as open cavity flow. Only exception is the cases where the flow and the cavity are positioned along the same direction. In these cases, as the streamlines also show that the fluid enters to the cavity from its center and exits from its edge. Therefore, the results also show that the position of the cavity is another parameter which affects the convective thermal conductance (or resistance).

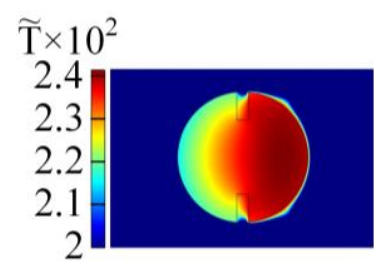

(a)
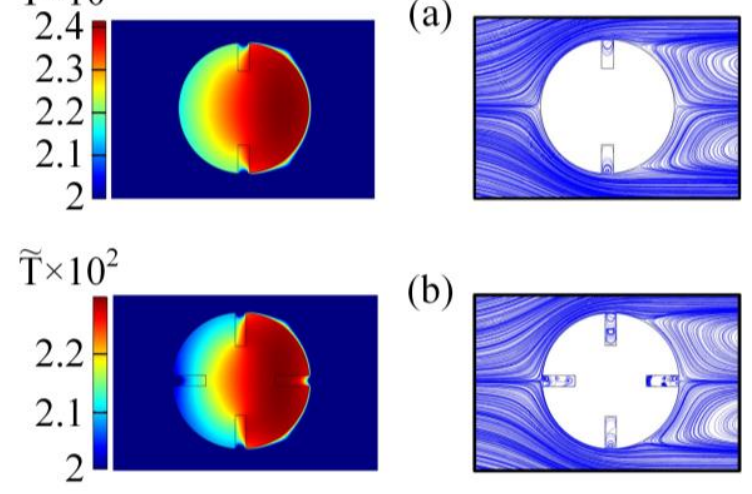

(b)
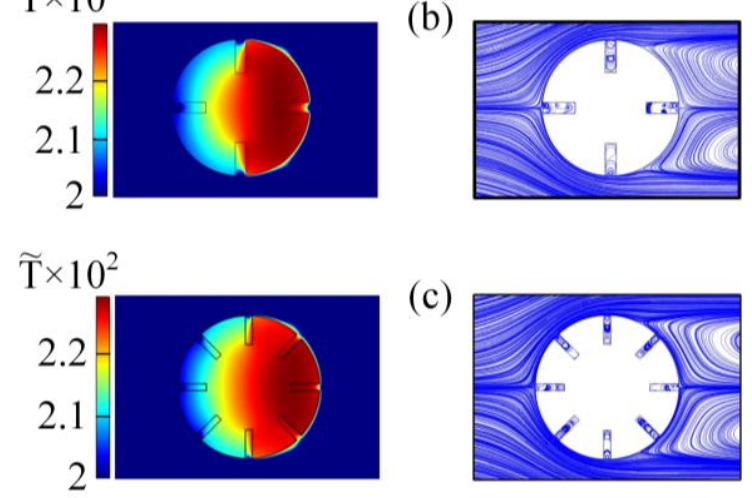

(c)

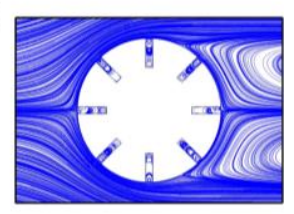

Figure 8. Temperature distributions and velocity streamlines for the best performing designs in the Fig. 9. (a) $\mathrm{H}_{\mathrm{cv}} / \mathrm{L}_{\mathrm{cv}}=0.42$, (b) $\mathrm{H}_{\mathrm{cv}} / \mathrm{L}_{\mathrm{cv}}=0.32$, (c) $\mathrm{H}_{\mathrm{cv}} / \mathrm{L}_{\mathrm{cv}}=0.24$ 
The results of both T-shaped fins and cavities show that the overall thermal resistance can be minimized by uncovering the best performing designs. The best performing design exists due to the two-conflicting behavior of the area on the heat transfer rate. Heat transfer rate would be expected to increase as the surface area increases. However, this increase also increases resistance to the fluid flow which yields to a decrease in the convective heat transfer coefficient. Therefore, the design corresponding to the minimum peak temperature exists as summarized in Fig. 9. Figure 9 documents the peak temperature relative to the Reynolds number for heat generating circular cylinders with only cavities, only T-shaped fins and without cavities and fins. The peak temperature is the greatest for the cylinder without fins and cavities and the smallest for the cylinder with fins. However, Figure 9 also shows that the difference in the peak temperature is the greatest with low Re number, and it decreases as the Re increases. For instance, the maximum difference in peak temperature is $60.08 \%$ and $21.57 \%$ for $\mathrm{Re}$ number 10 and 400, respectively.

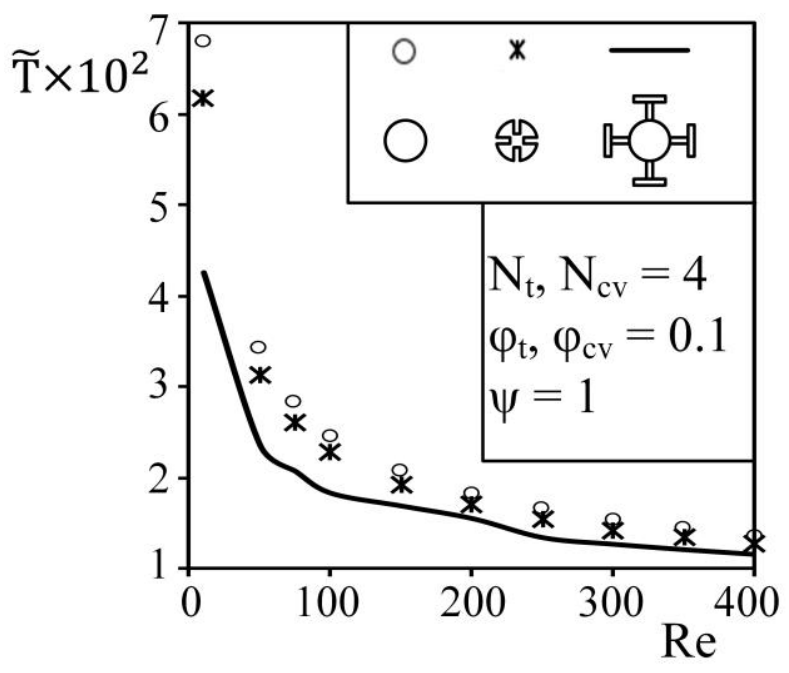

Figure 9. The effect of Re number on the peak temperature for the competing configurations in cross-flow

\section{PARALLEL-FLOW}

\subsection{T-shaped fins}

\subsubsection{Model}

Consider a 3-dimensional heat generating cylinder, $\pi \times \mathrm{R}^{2} \times \mathrm{W}_{\mathrm{c}}$, with four T-shaped fins, $\left(\mathrm{L}_{1}, \mathrm{t}_{1}, \mathrm{~W}_{\mathrm{t}}\right)$ and $\left(\mathrm{L}_{0}, \mathrm{t}_{0}\right.$, $\mathrm{W}_{\mathrm{t}}$ ), inserted in a fluid domain with the scales of $\mathrm{H}_{\mathrm{f}} \times \mathrm{L}_{\mathrm{f}} \times \mathrm{W}_{\mathrm{f}}$. Length scales of the width of the geometry $\left(\mathrm{W}_{\mathrm{t}}, \mathrm{W}_{\mathrm{f}}, \mathrm{W}_{\mathrm{c}}\right)$ equals to $(6 \times \mathrm{R})$. Inlet and outlet surfaces are perpendicular to the cylinder's base and top surfaces, i.e. fluid flows along the circular cylinder, the distance in between tip of fins and symmetry planes were kept constant as $\mathrm{R} / 2$ throughout the analyses for the sake of simplicity. Three-dimensional Navier-Stokes and Energy equations were solved numerically. The governing equations are similar to the equations discussed in Section 2.2.1. However, because the problem is three-dimensional, the conservation of the momentum along the width direction (z-direction) and the derivatives along that direction are inserted such as $\partial \mathrm{w} / \partial \mathrm{z}$, $w \partial \mathrm{u} / \partial \mathbf{z}, \partial^{2} \mathrm{u} / \partial \mathbf{z}^{2}, w \partial \mathrm{v} / \partial \mathbf{z}, \partial^{2} \mathrm{v} / \partial \mathbf{z}^{2}, w \partial w / \partial \mathbf{z}, \partial \mathbf{P} / \partial \mathbf{z}, \partial^{2} w / \partial \mathbf{z}^{2}$, $\mathrm{w} \partial \mathrm{T} / \partial \mathrm{z}$ and $\partial^{2} \mathrm{~T} / \partial \mathrm{z}^{2}$.

The non-dimensionalization parameters of Eq. (6) were used to non-dimensionalize the governing equations. Therefore, the dimensionless governing equations have the same format, i.e. the multiplication constants with the terms are the same. Please note that the conservation of the momentum along the z-direction is inserted, and the multiplication constant of the derivative terms along the $\mathrm{z}$ direction are the same with the terms are being summed with those derivatives.

\subsubsection{Results}

Figure 10 shows the effect of different parameters on the peak temperature. For instance, Figure 10a shows the effect on the thermal performance for different two $\mathrm{L}_{1} / \mathrm{L}_{0}$ ratios. The fins become slender (i.e., long and thin) as $\psi$ increases. Schematic drawing of the heat generating cylinder with attached fins can be seen in Fig. 10c. Unlike the cross flow configurations, fluid is flowing along the cylinder. In addition, Figure 10a shows that decreasing $\psi$ decreases the minimum peak temperature. Therefore, slender fins with thick stems corresponds to the smallest resistance for the heat flow. Furthermore, Figure 10a shows that the effect of $\psi$ becomes more pronounced as the $\mathrm{L}_{1} / \mathrm{L}_{0}$ ratio increases. However, the peak temperature is minimum with the smallest $\mathrm{L}_{1} / \mathrm{L}_{0}$ ratio and $\psi$. Here, the smallest $\mathrm{L}_{1} / \mathrm{L}_{0}$ ratio was selected as 0.5 in order to eliminate the branches to overlap.

Figure $10 \mathrm{~b}$ shows the effect of $t_{1} / t_{0}$ on the peak temperature for various $L_{1} / L_{0}$ ratios when $\psi$ is 1 . Increasing the $t_{1} / t_{0}$ ratio decreases the peak temperature for all $L_{1} / L_{0}$ ratios. However, increasing the $t_{1} / t_{0}$ ratio from 1 to 5 yields a steep decrease, then the effect of $t_{1} / t_{0}$ ratio on the peak temperature begins to diminish. In addition, this diminishing is more pronounced as $\mathrm{L}_{1} / \mathrm{L}_{0}$ ratio increases. Furthermore, Figure $10 \mathrm{~b}$ also shows that the peak temperature decreases and $\mathrm{t}_{1} / \mathrm{t}_{0}$ ratio increases.

Figure $10 \mathrm{c}$ documents the effect of $\mathrm{L}_{1} / \mathrm{L}_{0}$ ratio on the peak temperature with the optimized $t_{1} / t_{0}$ ratios of Fig. 10b. Figure 10 c explicitly shows that increasing the $\mathrm{L}_{1} / \mathrm{L}_{0}$ ratio increases the peak temperature which is inferred in Fig. 10b. In addition, Figure 10c also shows that the relation between the $\mathrm{L}_{1} / \mathrm{L}_{0}$ ratio and the peak temperature is power law with less than 1. Overall, Figure 10 documents that decreasing $\psi$ and $\mathrm{L}_{1} / \mathrm{L}_{0}$ ratio and increasing $\mathrm{t}_{1} / \mathrm{t}_{0}$ ratio decrease the peak temperature in the heat generating cylinder.

\subsection{Cavities}

\subsubsection{Model}

Consider a 3-dimensional cylindrical heat generating domain with the size of $\pi \times \mathrm{R}^{2} \times \mathrm{W}_{\mathrm{c}}$ similar to the section 3.1.1. Four cavities $\left(\mathrm{N}_{\mathrm{cv}}=4\right)$ were inserted into the heat generating domain with the size of $\mathrm{H}_{\mathrm{cv}} \times \mathrm{L}_{\mathrm{cv}} \times \mathrm{W}_{\mathrm{cv}}$. Fluid enters to the 3dimensinal unit flow domain which surrounds the heat generating cylinder, and then it flows along the cylinder, i.e. parallel flow. The top, bottom, left and right boundaries of the elemental flow domain which surrounds the cylinder was specified as symmetry boundaries because it is a representative elemental domain. In addition, the length of the heat generating domain $\left(\mathrm{W}_{\mathrm{c}}\right)$ is fixed as six times the radius of the cylinder which is the same width specified in Section 3.1.1. The spacing in between the cylinder and symmetry boundaries were also fixed as $3 / 2 \times \mathrm{R}$. The $3-\mathrm{D}$ conservation of mass, momentum and energy equations were 
solved numerically in dimensionless form. The governing equations are similar to the equations solved in Section 3.1.1. However, as discussed in Section 2.2.1, due to the absence of the fins, the energy equation for the fins and the conservation of the energy at the fin interfaces diminish.
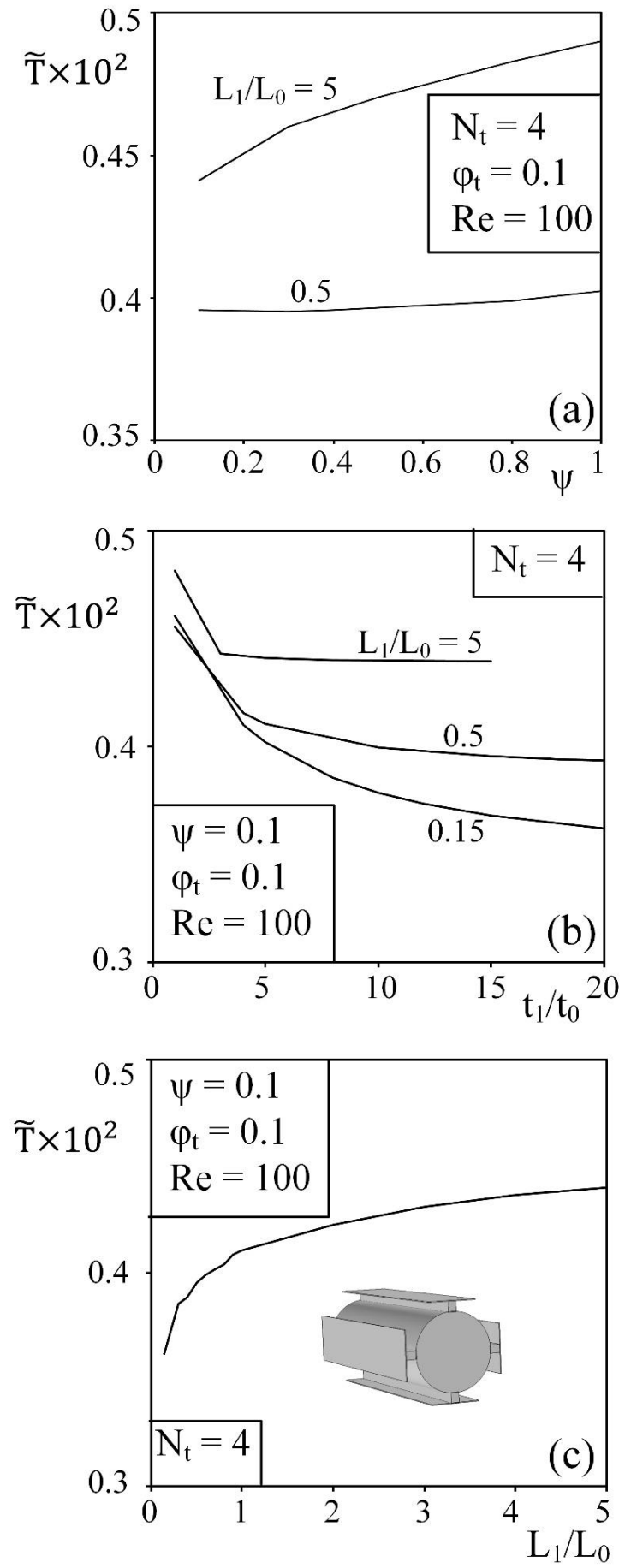

Figure 10. The maximum excess temperature of 3-D domain with fins in parallel flow relative to (a) $\psi$, (b) $t_{1} / t_{0}$, , c) $\mathrm{L}_{1} / \mathrm{L}_{0}$

\subsubsection{Results}

Figure 11 shows how the length scales of the cavity affect the peak temperature in the heat generating domain where the volume of the cavities is fixed. Figure 11 shows that thinner and longer cavity shapes (i.e., low $\mathrm{H}_{\mathrm{cv}} / \mathrm{L}_{\mathrm{cv}}$ ratios) correspond to low peak temperature values. Increasing the $\mathrm{H}_{\mathrm{cv}} / \mathrm{L}_{\mathrm{cv}}$ ratio increases the peak temperature. However, increasing $\mathrm{H}_{\mathrm{cv}} / \mathrm{L}_{\mathrm{cv}}$ from 0.1 to 0.8 increases the peak temperature around $4 \%$.
Figure 11 also shows that in parallel flow case the cavities begin almost near the origin of the cylinder provides the smallest peak temperature. Therefore, unlike in the crossflow case, the convective heat transfer coefficient is almost uniform and the shape optimization yields to decrease in the conductive resistances in between the cavity surface and the heat generating domain. Therefore, the results of Fig. 11 is in accord with the results of Ref. [26] where the convective heat transfer coefficient was specified for the cavity surfaces. In addition, unlike in the cross-flow cases, the peak temperature occurs in the middle of the cylinder because the cooling outside of the cylinder is uniform throughout the heat generating surface.

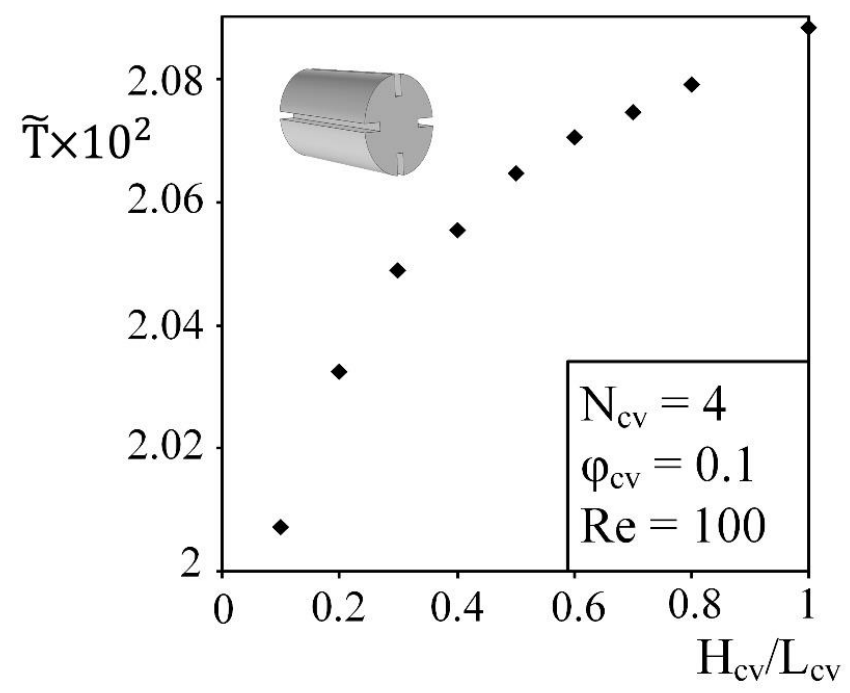

Figure 11. The effect of $\mathrm{H}_{\mathrm{cv}} / \mathrm{L}_{\mathrm{cv}}$ on the peak temperature

\section{CONCLUSIONS}

This study shows that the peak temperature of a uniformly heated cylinder can be minimized via using the rectangularshaped cavity or T-shaped fin with the fixed area fraction and the variable length scales for both the fins and the cavities. This study also shows that how the geometries of cavities and fins corresponding to the minimum peak temperature should be altered as the flow type changes (i.e., parallel and cross-flow). The minimization of the thermal resistances (temperature difference/heat transfer rate) yields heat transfer rate enhancement when the heat transfer is due to constant temperature difference.

For instance, the optimal fin geometry becomes long and thin for the cross-flow case while it has thick and short stem and slender tributaries for the parallel flow when $\mathrm{N}_{\mathrm{t}}=4$. In addition, the cavity geometry which minimizes the excess temperature for the cross-flow case is thicker and shorter than the one studied in the parallel flow case with the same number of cavities. In cross-flow case, the fins perform $20 \%$ better ( $20 \%$ decrease in the excess temperature) than cavities when $\mathrm{N}_{\mathrm{t}}$ and $\mathrm{N}_{\mathrm{cv}}$ are 4. Moreover, this difference increases up to $82 \%$ in parallel flow. This study also shows that increase in the number of the fins and/or cavities increases the thermal conductance, however, this increment decreases the effect of length scale ratios on the thermal performance. For instance, the peak temperature values of the best and the worst performing fin geometries yields 30.74 and $11.7 \%$ difference when $\mathrm{N}_{\mathrm{t}}=2$ and $\mathrm{N}_{\mathrm{t}}=8$, respectively. Likewise, for 
the cavity models it becomes 7.4 and $5.8 \%$ with $\mathrm{N}_{\mathrm{cv}}=2$ and $\mathrm{N}_{\mathrm{cv}}=8$, respectively. Furthermore, as the number of fins and cavities increase the effect of new additions of fins or cavities on the thermal performance diminishes. Reynolds number also affects the thermal performance of the fins and cavities. Excess temperature decreases as the Re number increases due to the increase in convective heat transfer coefficient (heat transfer coefficient is a function of $\mathrm{Re}$ number). In addition, here authors also uncovered that using the constant convective heat transfer coefficient as a boundary condition corresponds to the parallel flow case when the cylinders are short enough to have almost constant convective heat transfer coefficient and negligible effect of the decrease in the temperature difference. Overall, this study documents the shape of the cavities and fins which corresponds to the maximum heat transfer rate for cross- and parallel-flows. There is a best performing design for a given set of flow type, constraints and assumptions. This result is in accord with the constructal law.

\section{ACKNOWLEDGMENT}

The authors thank to the reviewers and editor for their constructive comments which improved the current text.

\section{REFERENCES}

[1] Yenigün O., Cetkin E. (2016). Constructal treeshaped designs for self-cooling, International Journal of Heat and Technology, Vol. 34, pp. S173-S178. DOI: $10.18280 /$ ijht.34S123

[2] Cetkin E., Oliani A. (2015). The natural emergence of asymmetric tree-shaped pathways for cooling of a non-uniformly heated domain, Journal of Applied Physics, Vol. 118, p. 024902. DOI: $\underline{10.1063 / 1.4926620}$

[3] Bejan A., Lorente S. (2008). Design with Constructal Theory, Wiley, Hoboken.

[4] Bejan A. (1997). Constructal-theory network of conducting paths for cooling a heat generating volume, International Journal of Heat and Mass Transfer, Vol. 40, pp. 799-816. DOI: 10.1016/0017-9310(96)00175$\underline{5}$

[5] Rehwinkel A. (2016). Corporate financial risk analysis according to the constructal law: Exploring the composition of liabilities to assets, International Journal of Heat and Technology, Vol. 34, pp. S133S140. DOI: $10.18280 /$ ijht.34S117

[6] Gonzalez J.M.M., Guerra Y.D.S., Garcia-Manso J.M., Arriaza E. (2016). Design and flow in basketball, International Journal of Heat and Technology, Vol. 34, pp. S51-S58. DOI: 10.18280/ijht.34S107

[7] Reis A.H., Miguel A.F., Aydın M. (2004). Constructal theory of flow architecture of the lungs, Medical Physics, Vol. 31, pp. 1135-1140. DOI: 10.1118/1.1705443

[8] Cetkin E. (2014). Three-dimensional highconductivity trees for volumetric cooling, International Journal of Energy Research, Vol. 38, pp. 1571-1577. DOI: $\underline{10.1002 / \mathrm{er} .3176}$

[9] Giannetti N., Rocchetti A., Saito K. (2016). Thermodynamic optimization of three-thermal irreversible systems, International Journal of Heat and Technology, Vol. 34, pp. S83-S90. DOI: $\underline{\text { 10.18280/ijht.34S110 }}$

[10] Bejan A., Almogbel M. (2000). Constructal T-shaped fins, International Journal of Heat and Mass Transfer, Vol. 43, pp. 2101-2115. DOI: 10.1016/S00179310(99)00283-5

[11] Lorenzini G., Moretti S. (2007) A CFD application to optimize T-shaped fins: Comparisons to the constructal theory's results, Journal of. Electronic Packaging, Vol. 129, pp. 324-327. DOI: $10.1115 / 1.2756852$

[12] Lorenzini G., Biserni C., Correa R.L., Dos Santos E.D., Isoldi L.A., Rocha L.A.O. (2014). Constructal design of T-shaped assemblies of fins cooling a cylindrical solid body, International Journal of Thermal Sciences, Vol. 83, pp. 96-103. DOI: 10.1016/j.ijthermalsci.2014.04.011

[13] Hazarika S.A., Bhanja D., Nath S., Kundu B. (2015). Analytical solution to predict performance and optimum design parameters of a constructal T-shaped fin, Energy, Vol. 84, pp. 303-316. DOI: $\underline{10.1016 / j . e n e r g y .2015 .02 .102}$

[14] Lorenzini G., Rocha L.A.O. (2006). Constructal design of Y-shaped assembly of fins, International Journal of Heat and Mass Transfer, Vol. 49, pp. 4552-4557. DOI: 10.1016/j.ijheatmasstransfer.2006.05.019

[15] Lorenzini G., Rocha L.A.O. (2009). Constructal design of T-Y-shaped assembly of fins for an optimized heat removal, International Journal of Heat and Mass Transfer, Vol. 52, pp. 1458-1463. DOI: 10.1016/j.ijheatmasstransfer.2008.09.007

[16] Lorenzini G., Corrêa R.L., dos Santos E.D., Rocha L.A.O. (2011). Constructal design complex assembly of fins, International Journal of Heat Transfer, Vol. 133, p. 081902. DOI: $\underline{10.1115 / 1.4003710}$

[17] Lorenzini G., Biserni C., Rocha L.A.O. (2013). Constructal design of $\mathrm{X}$-shaped conductive pathways for cooling a heat generating domain, International Journal of Heat and Mass Transfer, Vol. 58, pp. 513520. DOI: 10.1016/j.ijheatmasstransfer.2012.11.040

[18] Lorenzini G., Barreto E.X., Beckel C.C., Schneider P.S., Isoldi L.A., dos Santos E.D., Rocha L.A.O. (2017). Geometrical evaluation of T-shaped high conductive pathway with thermal contact resistance for cooling of heat-generating medium, International Journal of Heat and Mass Transfer, Vol. 108, pp. 1884-1893.

DOI: 10.1016/j.ijheatmasstransfer.2017.01.008

[19] Cetkin E. (2015). Constructal vascular structures with high-conductivity inserts for self-cooling, Journal of Heat Transfer, Vol. 137, p. 111901. DOI: 10.1115/1.4030906

[20] Biserni C., Rocha L.A.O., Bejan A. (2004). Inverted fins: geometric optimization of the intrusion into a conducting wall, International Journal of Heat and Mass Transfer, Vol. 47, pp. 2577-2586. DOI: 10.1016/j.ijheatmasstransfer.2003.12.018

[21] Rocha L.A.O., Lorenzini E., Biserni C. (2005). Geometric optimization of shapes on the basis of Bejan's constructal theory, International Communications in Heat and Mass Transfer, Vol. 32, pp. 1281-1288. DOI: 10.1016/j.icheatmasstransfer.2005.07.010 
[22] Xie Z., Chen L., Sun F. (2010). Geometry optimization of T-shaped cavities according to constructal theory, Mathematical and Computer Modelling, Vol. 52, pp. 1538-1546. DOI: 10.1016/j.mcm.2010.06.017

[23] Lorenzini G., Biserni C., Estrada E.D., Isoldi L.A., Dos Santos E.D., Rocha L.A.O. (2014). Constructal design of convective Y-shaped cavities by means of genetic algorithm, Journal of Heat Transfer, Vol. 136, p. 071702. DOI: $10.1115 / 1.4027195$

[24] Lorenzini G., Rocha L.A.O. (2009). Geometric optimization of T-Y-shaped cavity according to Constructal design, International Journal of Heat and Mass Transfer, Vol. 52, pp. 4683-4688. DOI: 10.1016/j.ijheatmasstransfer.2009.06.020

[25] Lorenzini G., Garcia F.L., Dos Santos E.D., Biserni C., Rocha L.A.O. (2012). Constructal design applied to the optimization of complex geometries: T-Yshaped cavities with two additional lateral intrusions cooled by convection, International Journal of Heat and Mass Transfer, Vol. 55, pp. 1505-1512. DOI: 10.1016/j.ijheatmasstransfer.2011.10.057

[26] Lorenzini G., Estrada E.S.D., dos Santos E.D., Isoldi L.A., Rocha L.A.O. (2015). Constructal design of convective cavities inserted into a cylindrical solid body for cooling, International Journal of Heat and Mass Transfer, Vol. 83, pp. 75-83. DOI: 10.1016/i.ijheatmasstransfer.2014.11.065

[27] COMSOL Multiphysics 5.0, COMSOL Inc., 2014.

\section{NOMENCLATURE}

A

$\mathrm{A}_{\mathrm{cv}}$

$\mathrm{c}_{\mathrm{p}}$

$\mathrm{H}$

$\mathrm{k}$ area of the cylindrical solid domain, $\mathrm{m}^{2}$, Fig. 1

total cavity area, $\mathrm{m}^{2}$

specific heat, J. $\mathrm{kg}^{-1}$. $\mathrm{K}^{-1}$

height, $m$

thermal conductivity, W. $\mathrm{m}^{-1} \cdot \mathrm{K}^{-1}$
L length, $\mathrm{m}$

$\mathrm{m} \quad$ index of mesh test

n normal vector

$\mathrm{N} \quad$ number of fins or cavities

q"' heat source, W. $\mathrm{m}^{-3}$

$\mathrm{R}$ radius of the cylinder, $\mathrm{m}$

$\mathrm{t} \quad$ thickness, $\mathrm{m}$

$\mathrm{T} \quad$ temperature, $\mathrm{K}$

$\mathrm{u}, \mathrm{v}, \mathrm{w} \quad$ velocity components corresponding to the spatial coordinates, $\mathrm{m}$. $\mathrm{s}^{-1}$

W width, $m$

\section{Greek symbols}

$\begin{array}{ll}\alpha & \text { thermal diffusivity, } \mathrm{m}^{2} \cdot \mathrm{s}^{-1} \\ \mu & \text { dynamic viscosity, } \mathrm{kg} \cdot \mathrm{m}^{-1} \cdot \mathrm{s}^{-1} \\ \nu & \text { kinematic viscosity, } \mathrm{m}^{2} \cdot \mathrm{s} \\ \rho & \text { density, kg. m} \mathrm{m}^{-3} \\ \varphi & \text { volume fraction } \\ \psi & \text { area fraction circumscribed by one T- } \\ & \text { shaped fin }\end{array}$

\section{Subscripts}

$\begin{array}{ll}0 & \text { tributary } \\ 1 & \text { stem } \\ \mathrm{c} & \text { cylinder } \\ \mathrm{cV} & \text { cavity } \\ \mathrm{f} & \text { fluid } \\ \max & \text { maximum } \\ \text { ref } & \text { reference } \\ \mathrm{t} & \text { fin }\end{array}$

\section{Superscripts}

dimensionless 